\title{
CARACTERIZACIÓN DE LAS CONDICIONES DEL DRENAJE Y DEL SUELO BASADA EN LA GEOMORFOLOGÍA Y EL TRATAMIENTO DIGITAL DE IMÁGENES (PARTIDO DE PUÁN, BUENOS AIRES. ARGENTINA)
}

\author{
CHARACTERIZATION OF DRAINAGE AND SOIL CONDITIONS BASED ON \\ GEOMORPHOLOGY AND DIGITAL IMAGE DATA PROCESSING (PUÁN \\ DISTICT, BUENOS AIRES PROVINCE. ARGENTINA)
}

\author{
Edgardo NAVARRO'(2) \\ Magdalena GONZALEZ URIARTE²
}

\begin{abstract}
RESUMO
A crescente demanda de produtos agrícolas e pecuários da última década gerou, no âmbito rural, a necessidade de melhorar a gestão dos recursos da água e do solo. Essa situação motivou um estudo destinado a caracterizar áreas geomorfológicas homogêneas, mediante a análise da cartografia topográfica, imagens multiespectrais e controles do terreno. A superfície corresponde ao Partido de Puán, Sudoeste de Buenos Aires, Argentina, com uma extensão de $6.389 \mathrm{~km}^{2}$ e uma população próxima a 18.700 habitantes. Trabalhou-se sobre a base de seis grandes unidades geomorfológicas, previamente diferenciadas por condições de relevo, drenagem e materiais superficiais, e aplicou-se o tratamento digital de imagens com o fim de determinar novos parâmetros descritivos na caracterização das mesmas. Especificamente, a aplicação do Color Look Up Table (CLUT) permitiu diferenciar, em linhas gerais, solos profundos de solos superficiais. A Análise dos Componentes Principais (ACP) fez destacáveis condutos de drenagens funcionais ou não, assim como também possibilitou agrupar corpos lacustres em duas categorias por profundidade. A interpretação direta no Infravermelho Refletido (IR) permitiu individualizar todos os setores cobertos por água e quantificá-los na área por unidade e para o total do Partido. Como comentário final, destaca-se a eficiente complementação desses modos de obtenção de dados, a análise geomorfológica e o tratamento digital de imagens multiespectrais sobre a base das unidades diferenciadas pelo primeiro. Isto torna possível estabelecer chaves de interpretação regional, que permitam reconhecimentos rápidos para a resolução de problemas concretos, que possam estender-se também a uma análise multitemporal.
\end{abstract}

Palavras-chave: tratamento digital de imagens, unidades geomorfológicas, Partido de Puán, Argentina.

$1 \quad$ Universidad Nacional del Sur - Departamento de Geología.

2 PAID - Comisión Investigaciones Científicas de la Provincia de Buenos Aires - Departamento de Geología, UNS. San Juan 670 (8000). Bahia Blanca. Argentina. enavarro@criba.edu.ar 


\section{EXTENDED ABSTRACT}

The Puán District is located in the southwestern part of Buenos Aires province in Argentina. It is an area of $6385 \mathrm{~km}^{2}$ with about 18700 in habitants. Puán (the county town), Darregueira, Bordenave, Villa Iris and 17 de Agosto are the main towns in the area. Growing concern over rural productivity during the last decade, requires a proper soil and water resources management. For this reason, the aim of this work is to acquire new descriptive parameters in order to characterize geomorphic homogeneous areas. For this purpose, geomorphic units were treated together with the satellital imagery visual analysis and the digital image data processing. The Geographic Information System IDRISI 32 was used. The geomorphic units had been previously defined from photocartography and the ground controls. Thus, Landsat Thematic Mapper Imagery (TM), path 227, row 086 and 087 , with radiometric and geometric distortions rectified, were used. The image geometry was corrected by identifying set of features on the ground that also were identified on the image. The ground control points were obtained by using Global Positioning System (GPS). Topographic Maps 1:100.000 and 1:50.000 scale and Satellital Charts scale 1:100.000 y 1:250.000 were used, which are included within IGM Santa Rosa (3763) and Bahia Blanca (3963) topographic maps, 1:500000 scale. The six large geomorphic units considered are included in two main landscapes (pampeano landscape at north and patagonico landscape at south). Llanura pedemontana (VLIp): It is defined from isoline of 250 metres above sea level (masl), good soil/ drainage conditions, mean freatic level $10 \mathrm{~m}$. Llanura noroccidental (VIIno): its boundary is defined by 250 and 170 masl altitudes, decreasing north-westward. High frecuency of ponds; soils of medium thickness and the freatic level depht varies from 10 to $3 \mathrm{~m}$. The chemical quality of groundwater is low. Llanura occidental (VIlo): its boundary is defined by the 250 and 150 masl altitudes, sloping down westward; drainage unconnected and highest frecuency of ponds. The chemical quality of groundwater decrease westward, the freatic level depth varies from 13 to 6 and the chemical quality of groundwater decrease toward lowest altitudes. Soils with low agronomic-capability because of the coarse texture and deficient rainfall input are present. Llanura suroccidental (VIIso): it is defined below 150 masl, the topography is irregular, with important fluvial dissection; thin soils and the freatic level depth highly variable $(50$ to $3 \mathrm{~m})$. Paleovalle complejo $(\mathrm{CpV})$ : the bottom of the paleovalley display the lowest altitudes in the area (+20 to $-20 \mathrm{~m}$ with respect to sea level), sandy soils, scarcely developed and freatic level depht highly variable (50 to $30 \mathrm{~m}$ ). Niveles escalonados 1 y 2 (NE 1 y 2): these are restricted geomophological surfaces associated with altitudes between 120 and 40 masl. Runoff not evident, freatic level depth between 40 and $30 \mathrm{~m}$. The chemical quality of groundwater is low. The first four units correspond to the pampeano landscape and the two last ones to the patagonico landscape. The digital image data processing produced the following results:By using the Near Infrared band (NI), the location and delimitation through the pixel's frequency histogram (figure 1), of the water bodies were precisely carried out (figure 2). In the same way, the areas used by the ponds in relation with each geomorphic units and with the whole District were estimated (table 1). The usage of Color Look Up Table (CLUT), (figure 3 and 4) allowed to differenciate shallow from deep soils. In the same way, subdivisions in geomorphic units, difficult to differenciate with a simple band, were identified. Bands 2, 3 and 4 constitute the best arrangement. Blue filter (spectral green), red filter (spectral red) and green filter (Near infrared) with contrast enhacement in image data by histogram equalization, were asigned to the bands respectively. The Principal Components Transformation (PC) of the image data made evident features not discernable in the original data, such as the drainage way functional character (figure 5) and changes of depth and/or sedimentary or saline load of the ponds (figure 6). A classification starting from the image's histogram of figure 6 (figure 7) was done. The dark tone indicates deeper water bodies and the grey tone shallower water bodies and lands without vegetation or with low photosinthetic activity (figure 8). The particularly components were obtained from the covariance matrix and the third principal component (3PC) was particulary used (table 2). Finally, the application of the geomorphic main interpretation together with multispectral images analysis, in digital and visual form, produced useful results. Thus, the arrangement of these two groups of data provided new keys for the regional interpretation, which might be extended to multitemporal analysis.

Key-words: digital image data processing, geomorphic unites, Puán District, Argentina.

\section{INTRODUCCIÓN}

La creciente presión sobre la productividad durante la última década ha generado la necesidad de optimizar la gestión de los recursos agua y suelo. Esta situación ha llevado a los autores a programar un amplio estudio destinado a evaluar factores de significación que faciliten el diagnóstico regional de estos recursos a distintas escalas de observación.

Debido a que la mayor eficiencia de gestión se consigue a partir de unidades políticas-administrativas denominadas partidos, esto genera la necesidad de 
conciliar aspectos regionales y locales, que condicionan una investigación en etapas, a fin de ubicar en el contexto general estos espacios territoriales más limitados.

El territorio en análisis se circunscribe al Partido de Puán situado en el sudoeste de la Provincia de Buenos Aires, entre $37^{\circ} 22^{\prime}$ y $38^{\circ} 49^{\prime}$ de latitud sur y $62^{\circ} 30^{\prime}$ a $63^{\circ}$ $23^{\prime}$ de longitud oeste, que cuenta con una extensión de $6.375 \mathrm{~km}^{2}$ y contiene una población próxima a 18.700 habitantes, según el último censo nacional (Indec 1991). Se destacan como centros urbanizados de importancia local Puán (ciudad cabecera), Darregueira, Bordenave, Villa Iris, 17 de Agosto y Felipe Solá.

Esta región que se caracteriza por una importante actividad agropecuaria, en especial de secano, aunque muy localizadamente existen sectores bajo riego de gravedad y más recientemente riego complementario con explotación de acuíferos libres.

La producción agrícola corresponde principalmente a cereales (cosecha fina) y en segunda a girasol y maíz. La ausencia de cursos fluviales significativos y una cierta restricción hídrica en el clima hacen que, tanto para la población rural como la suburbana se abastezcan principalmente de estos acuíferos.

Las bases que fundamentan el presente estudio se centran en la interrelación del paisaje, a través de la geomorfología, y las posibilidades que ofrece la teledetección. Consecuentemente, se plantea como objetivo mejorar la caracterización de áreas geomórficas homogéneas, logradas por estudios anteriores, a partir del análisis fotocartográfico y controles de terreno. En dicha delimitación, los elementos considerados fueron aspectos de relieve, drenaje superficial, agua freática y hechos de cobertura. Con el fin de identificar nuevos parámetros descriptivos, se vincularon las unidades geomórficas, con texturas, patrones fotográficos y respuestas espectrales específicas a través del análisis visual y digital de imágenes satelitales.

\section{MATERIALES Y MÉTODOS}

La metodología se basa en el análisis visual y digital de dos imágenes multiespectrales del sensor Tematic Mapper (TM) del sistema Landsat, path 227 y row 086 y 087 de fecha 06 de enero de 1999 (EDC 1999). Se trabajó con las siete bandas en formato digital, con nivel de procesamiento 4 que comprende correcciones radiométricas y geométricas por movimientos de plataforma y sensor. Los puntos de control fueron referenciados con geoposicionador satelital (GPS), lo que permitió integrar la información multiespectral con la de cartografía topográfica regular. Esta última correspondiente a cartas topográficas, en escalas $1: 50.000$ y 1:100.000 y cartas satelitales en escalas 1:100.000 y 1:250.000 todas pertenecientes a las hojas 1:500000 Santa Rosa (3763) y Bahía Blanca (3963) del Instituto Geográfico Militar (IGM 1957-1972 y 1999).

Además, se procedió al análisis crítico de la bibliografía regional y temática que se cita en las referencias y se complementó la descripción con reconocimientos de terreno, en donde se realizó la toma de datos con GPS Garmin III Plus, a los efectos de la corrección de la geometría de las imágenes.

El tratamiento digital de imágenes raster y vectoriales se realizó con el software Idrisi 32 (Clark Labs 1999), y se empleó el Corel Draw 9 como soft de apoyo. Debido a que las imágenes raster son matrices numéricas, facilitó componerlas de distinta manera, permitiendo delimitar las unidades morfológicas previamente definidas (González Uriarte et al. 2000), como así también, el desarrollo de operaciones matemáticas para la definición de subunidades. La denominación de los suelos está referida al Soil taxonomy (Soil Survey Staff 1999).

\section{MARCO GEOAMBIENTAL}

El área reconocida tiene fundamentalmente un desarrollo latitudinal, abarcando dos tipos de paisajes distintivos en diferente grado de extensión (González Uriarte et al. 2000). Las porciones centro y norte, morfológicamente corresponden a una planicie alta, que se desarrolla entre los 250 y 350 metros sobre el nivel del mar (msnm), es representativa del paisaje pampeano y en lo estructural está controlada por el Positivo de Ventania. El sector meridional, que comprende el cuarto restante de la superficie de estudio, corresponde a la unidad estructural Cuenca del Colorado y se identifica con el paisaje patagónico, variando notablemente las condiciones de relieve, drenaje y materiales superficiales respecto de la unidad anterior.

El clima según la clasificación de Köppen-Geiger (Strahler \& Strahler 1989) corresponde al tipo Bsk, caracterizado como seco, de estepa, con temperatura media anual inferior a $18^{\circ} \mathrm{C}$ y en cuanto al régimen climoedáfico es mésico y está en la transición de údico (en el norte) a ústico (al sur) (Van Wanbecke \& Scoppa 1980). El régimen hídrico se caracteriza por una marcada gradación con valores, de $700 \mathrm{~mm} / \mathrm{año} \mathrm{en} \mathrm{el} \mathrm{noreste} \mathrm{a}$ menos $500 \mathrm{~mm} / a$ ño en el sur. Teniendo en cuenta el índice hídrico de Thornthwaite (Forte Lay et al. 1989) el territorio se sitúa entre valores 0 y -20 .

Es de destacar que en las últimas tres décadas, ha habido un incremento en la pluviosidad, lo que estimuló 
a avanzar con agricultura en forma imprudente en los climas menos aptos, lo que generó fenómenos de mayor riesgo erosivo y disminución de la productividad. Esta tendencia negativa se intenta neutralizar en la actualidad mediante la implementación de riego complementario, lo que seguramente va a generar nuevos riesgos de degradación si no se realiza de forma planificada. La vegetación nativa forma parte de las unidades fitogeográficas "del espinal"y "pampeana" (Cabrera 1976), siendo característica del área la mezcla de arbustos peremnifolios, dominantes en el oeste y el pastizal de gramíneas bajas y herbáceas, en el este. En relación a los cultivos, como se citó, predominan la producción de granos y forrajeras en el área pampeana y en la patagónica, persiste en mayor grado, el monte de arbustos peremnifolios asociado con vegetación psammófila en áreas arenosas y halófilas en las depresiones salinizadas.

\section{CONDICIONES DE RELIEVE, DRENAJE SUPERFICIAL Y SUELOS}

En lo que hace al área de paisaje pampeano que comprende un $80 \%$ de la superficie del partido, la llanura se desarrolla en un rango entre los 300 y 100 msnm, irradiando suavemente desde el noreste, estribaciones del cordón serrano de Puán, hacia el noroeste y sudoeste, con gradiente siempre menores al $1 \%$. En esta porción se diferencian como unidades geomórficas una orla de piedemonte donde es notable la infiltración de pequeños cursos provenientes del sistema de Ventania y distalmente la planicie general caracterizada por un drenaje lacunar subdividisible a su vez, en dos unidades de acuerdo al sentido general de los escurrimientos.

La llanura noroccidental queda definida por una tendencia de flujo hacia el noroeste y la llanura occidental manifiesta sentidos de alineamiento practicamente esteoeste, caracterizándose esta, en visión de conjunto, por condiciones de drenaje lacunar muy acentuado. La última unidad reconocida para el área pampeana, que aún forma parte de la planicie alta representando casi un tercio de la misma, se caracteriza por una clara integración del drenaje y una marcada profundización de los escurrimientos que aportan al arroyo Chasicó, único sistema fluvial de la zona estudiada.

El perfil geomorfológico en la unidad de la llanura, es más o menos constante y según se ve en los cortes expuestos, está integrado en la base por una limolita compactada reconocida regionalmente como pampeano y coronada por una potente capa de tosca en plancha (superficie finipampeana). Sobreyacen en discontinuidad erosiva, depósitos eólicos modernos postpampeanos, en general definidos como loess arenoso, de espesor promedio al metro, adelgazados en las lomadas y que pueden adquirir varios metros en las hondonadas, labradas por erosión fluvial antigua o en el piedemonte (González Uriarte 1984). La distribución de los suelos responde a los aspectos reseñados de relieve, drenaje, materiales y clima, hacia el este del Partido predominan las asociaciones de Haplustol y Argiustol, en los subgrupos típico, éntico y lítico. Hacia el oeste, las menores precipitaciones dan predominio al Haplustol éntico y al Paleustol petrocálcico (Inta 1989).

Hacia el límite sur del paisaje pampeano es evidente una ruptura de gradiente a valores de hasta el $10 \%$ que cubren un área en pendiente con desniveles próximos a los 100 metros. Bajo estas condiciones se da el pasaje de la morfología pampeana a la patagónica, que para el área tiene una representatividad de aproximadamente el 20\%.

En esta última porción del territorio analizado, la topografía se hace más accidentada y son notables los cambios en el perfil geomorfológico. Subdivisibles en tres geoambientes, se destacan distintos niveles relícticos de planicie, un gran cuerpo lacunar, asociado al nivel más deprimido e invasiones arenosas de algunas decenas de metros de espesor. Los suelos presentan texturas más gruesas y perfiles más variados, en las superficies reconocidas como primero y segundo nivel, predominan el Calciustol petrocálcico y el Haplustol éntico, en las áreas en pendiente es característico el Haplustol éntico, siendo característico en las áreas en pendiente el Haplustol éntico y en los sectores arenosos el Ustortent y el Ustipsament.

\section{GEOAMBIENTES}

Participando de la morfología general descripta, desde el norte hacia el sur, han sido identificados (González Uriarte et al. 2000) seis grandes geoambientes, que se confirman en el análisis de imágenes y cuya altitud se expresa en metros sobre el nivel del mar (msnm).

Llanura Pedemontana (VLIp). Conforma el piedemonte serrano comprendiendo las tierras por sobre la cota de $250 \mathrm{msnm}$. Se caracteriza por buena condición de suelo-drenaje superficial, una profundidad media del nivel freático de 10 metros.

Llanura Noroccidental (VIIno). Nuclea tierras comprendidas entre los 250 y $170 \mathrm{msnm}$, presenta manifiesto régimen lacunar, altitud decreciente hacia el noroeste y suelo de mediano espesor. A medida que se desciende en altitud, el agua freática es de menor calidad y se alla progresivamente más cercana a la superficie (10 a 3 metros). 
Llanura Occidental (VIlo). Con altitudes entre 250 y $150 \mathrm{msnm}$, corresponde a tierras que decrecen hacia el oeste y se caracterizan por ausencia de integración del drenaje superficial y la máxima frecuencia de lagunas. En el mismo sentido que la pendiente decrece la profundidad del agua freática (13 a 6 metros) y baja notablemente la calidad química del recurso. En cuanto a los suelos es evidente su menor valor agronómico por la presencia de una textura más gruesa y menor pluviosidad.

Llanura Suroccidental (VIlso). Se desarrolla por debajo de los $150 \mathrm{msnm}$ de altitud y llega hasta el nivel de ruptura de gradiente que marca la transición al paisaje patagónico. Se diferencía de las unidades anteriores por una importante disección fluvial que aporta al sistema endorreico de Chasicó. Controlado por el recorte topográfico, el nivel freático oscila de profundo a medianamente superficial (35 a 6 metros), fluctuando también mucho las sales solubles totales.

Paleovalle Complejo (CpV). Unidad que se encuentra ya en el paisaje patagónico, reúne las cotas mínimas del área de estudio y su plano de fondo varía entre +20 y -20 metros respecto del nivel del mar, lugar en el que se localiza la laguna Chasicó. Debido al parcial relleno por arenas eólicas y el comportamiento concentrador de aguas de escurrimientos, el nivel freático es variable (50 y 3 metros). Por lo general la calidad de las aguas es mala.

Niveles Escalonados 1 y 2 (CNe1y2). Corresponde a superficies geomórficas restringidas con altitudes variables entre 40 y $120 \mathrm{msnm}$, que se diferencian por un resalto constante entre ambas de 20 metros. No ofrecen evidencia de drenaje superficial y el nivel freático en general es profundo (entre 30 y 40 metros), persistiendo una mala calidad de aguas.

\section{DISCUSIONES Y RESULTADOS}

\section{EMPLEO DE IMÁGENES VECTORIALES Y RASTER}

La primera operación consistió en la transferencia planimétrica de los rasgos lineales, como el límite geográfico del partido y las isolineas de la representación topográfica, para ello se obtuvieron imágenes vectoriales mediante la digitalización de la cartografía analógica mencionada precedentemente, con el empleo de una tableta digitalizadora Genius.

Cumplida la delimitación del área de trabajo, en una segunda etapa fue necesario transformar en imagen raster binaria el límite del Partido y el área encerrada, a los efectos de obtener directamente la imagen raster de la superficie en estudio en cada una de las bandas espectrales. De esta manera, todas las operaciones que se desarrollaron a futuro, tuvieron este área como unidad de referencia, ya sea para cuantificar o para la realización de la interpretación visual y automática. Esta imagen binaria se obtuvo mediante una operación de trasformación y reclasificación, en la que se asignó un identificador 1, para el área interna al límite y un identificador 0, para el valor de los píxeles externos al mismo.

Debido a que las imágenes satelitales carecían de corrección en su geometría, la misma se llevó a cabo con el apoyo de datos obtenidos en terreno con geoposicionador satelital, y en gabinete, con el aporte de las cartas imagen del Instituto Geográfico Militar de escala 1:100.000 (IGM 1996). En todos los casos, los puntos seleccionados fueron puntos notables, de fácil reconocimiento sobre las imágenes, asociados a rasgos conspicuos, como es la intersección de caminos y procurando que la distribución de los mismos fuera lo más homogénea posible a fin de minimizar el error final en la corrección realizada.

Debido a que el registro del Partido de Puán está comprendido en dos imágenes (row 086 y 087), se concatenaron ambas, lo que permitió trabajar con una única imagen integrada. De esta manera, y luego de definir en las siete bandas la ventana que contiene a la superficie del Partido, se procedió a realizar el análisis digital unificadamente para la totalidad del área en estudio. Para restringir la imagen exclusivamente al límite del Partido, se procedió a una operación de multiplicación, pixel a pixel, entre la ventana de cada banda que contiene al Partido y la imagen booleana del límite.

\section{INTERPRETACIÓN DIRECTA EN INFRARROJO ESPECTRAL (BANDA 4)}

Para la delimitación y cuantificación de los diferentes cuerpos lacunares, se trabajó con el infrarrojo cercano, banda 4 del TM $(0.76$ a $0.90 \mathrm{~mm}$ de longitud de onda). Para esto se generó una imagen booleana, a partir de la reclasificación del área de la ventana y de esta forma, fueron reasignados con el identificador 1 , todos aquellos valores de pixel comprendidos entre 0 y 40 de reflectancia, mientras que al resto de los pixeles se les asignó el identificador 0 .

La elección de este intervalo $(0$ - 40) que permite identificar superficies lacunares fue realizada en función del análisis del histograma de frecuencia (figura1) de la mencionada banda 4, donde se puede apreciar a este intervalo como un grupo destacable. Por otra parte, y a los efectos de diferenciar el entorno de 
la laguna de la superficie cubierta por agua, se compararon valores de los pixeles de este entorno con los del intervalo de referencia, evidenciando un fuerte contraste, hecho que permite identificar con mayor seguridad los límites lacunares, en especial en los cuerpos principales.

Esta nueva imagen resalta claramente la ubicación y distribución espacial de los diferentes cuerpos de agua superficiales, dentro de los que se pueden destacar por su magnitud e importancia recreativa las lagunas de Puán y Chasicó, y en menor medida la de Erize y permitirá seguimientos evolutivos al aplicar este análisis multitemporalmente. Por otra parte y con el propósito de conocer el valor areal actual de conjunto o individual, en el caso de lagunas principales, se procedió a dar un identificador para cada grupo de pixeles que definen cada laguna, hecho que deja abierta la posibilidad a futuro de estudios a escala de mayor detalle.

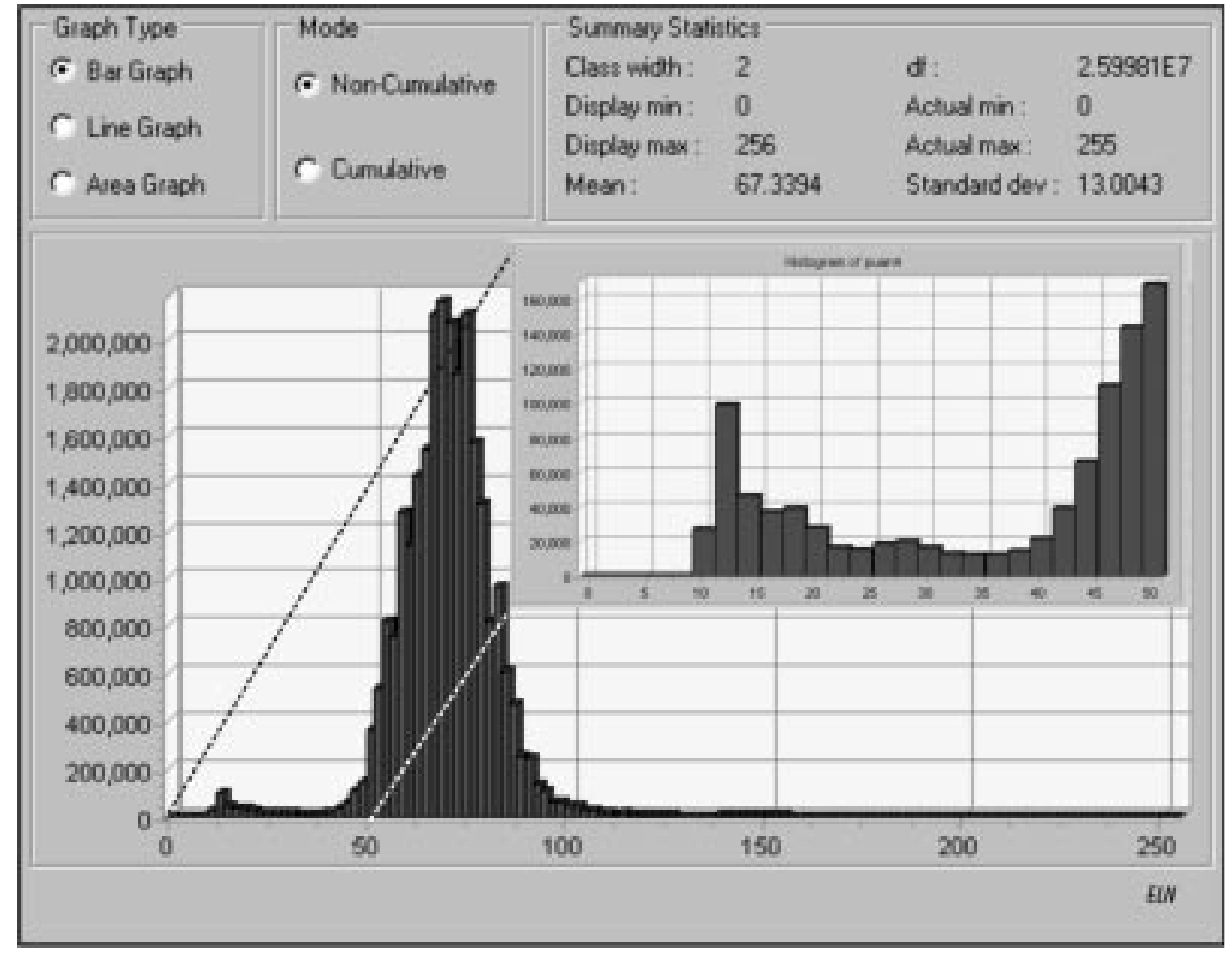

Figura 1: Histograma de la banda 4. Image histogram of Band 4.

Debido al comportamiento absortivo del agua en el infrarrojo cercano con relación a los otros tipos de cobertura del área, fue posible además de la localización y delimitación, cuantificar los cuerpos lacunares presentes. Se ilustra en la figura 2 la situación de cuerpos lacunares y en la tabla 1, los valores de representatividad areal, en valores absolutos y porcentuales, de los espejos de agua agrupados por unidad geomorfológica y para el total de la superficie del Partido.

\section{APLICACIÓN DE CLUT}

Una tabla de referencia del color o Color Look Up Table (CLUT), de acuerdo a Chuvieco (2000), es una matriz numérica que indica el Nivel Visual (NV) con que se representa en pantalla cada uno de los niveles digitales (ND) de la imagen, para tres bandas preseleccionadas, lográndose combinaciones en color multibanda y visualización seudocoloreada. 
Tabla 1: Representatividad areal, en valores absolutos y porcentuales, de cuerpos de agua por unidad geomorfológica y para el total del partido. Areal representativity, in absolute and percentage values of the water bodies for each geomorphic unit and District.

\begin{tabular}{|c|c|c|c|c|c|}
\hline \multirow{3}{*}{$\begin{array}{l}\text { UNIDAD } \\
\text { GEOMÓRFICA/ } \\
\text { GEOMORPHIC } \\
\text { UNITS }\end{array}$} & \multicolumn{5}{|c|}{ AREA/AREA } \\
\hline & \multicolumn{2}{|c|}{$\begin{array}{c}\text { CUBIERTA POR } \\
\text { AGUA/TO COVER WITH } \\
\text { WATER }\end{array}$} & \multicolumn{2}{|c|}{$\begin{array}{c}\text { LIBRE DE } \\
\text { AGUA/ WITHOUT } \\
\text { WATER }\end{array}$} & \multirow{2}{*}{$\begin{array}{c}\text { TOTAL } \\
\text { U.G./TOTAL } \\
\text { G.U. } \\
\text { ha }\end{array}$} \\
\hline & ha & $\%$ & ha & $\%$ & \\
\hline \multicolumn{6}{|l|}{$\begin{array}{l}\text { POSITIVO DE } \\
\text { VENTANIA }\end{array}$} \\
\hline VLIp & 41.67 & 0.19 & 21695.04 & 99.81 & 21736.71 \\
\hline VLIno & 3897.27 & 3.85 & 97428.24 & 96.15 & 101325.51 \\
\hline VLLo & 5966.91 & 2.73 & 212532.48 & 97.27 & 218499.39 \\
\hline VLLso & 526.86 & 0.30 & 177235.20 & 99.70 & 177762.06 \\
\hline \multicolumn{6}{|l|}{$\begin{array}{l}\text { CUENCA } \\
\text { DEL } \\
\text { COLORADO }\end{array}$} \\
\hline $\mathrm{CpV}$ & 1693.62 & 2.12 & 78239.70 & 97.88 & 79933.32 \\
\hline $\mathrm{CNe} 1$ y 2 & 6.75 & 0.02 & 38278.98 & 99.98 & 38285.73 \\
\hline TOTAL & & & & & 637542.72 \\
\hline
\end{tabular}

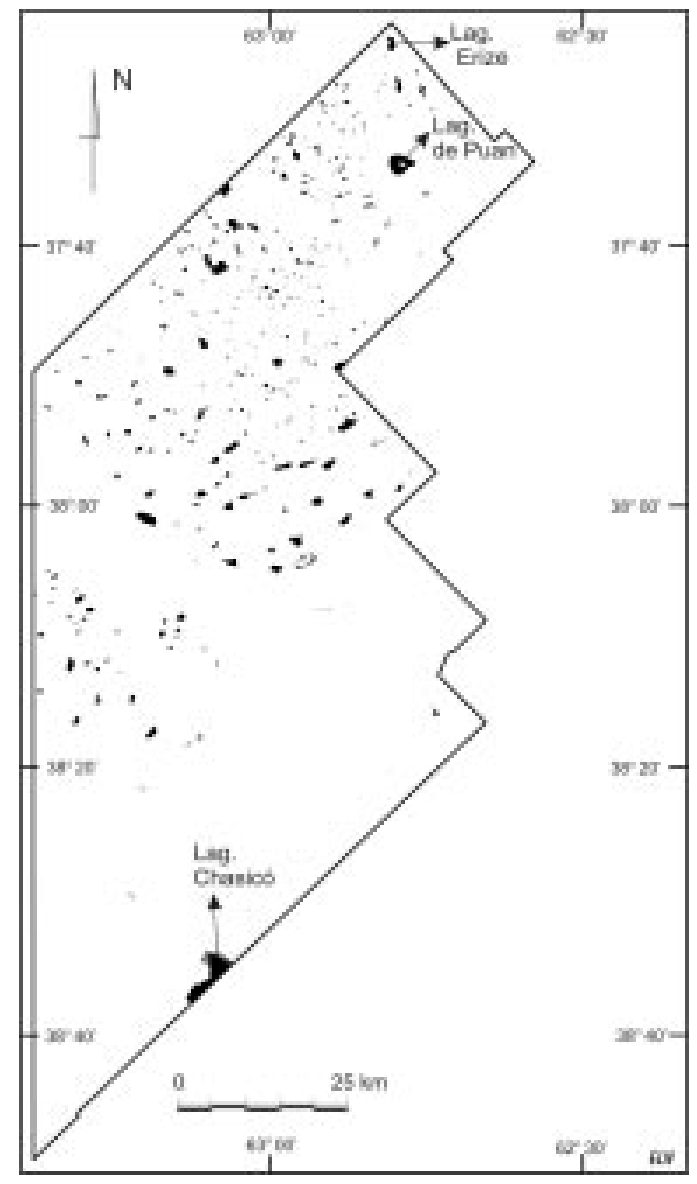

Figura 2: Distribución de los cuerpos lacunares por clasificación de la imagen del infrarrojo cercano. Distribution of the water bodies by classification of the Near infrared band. 


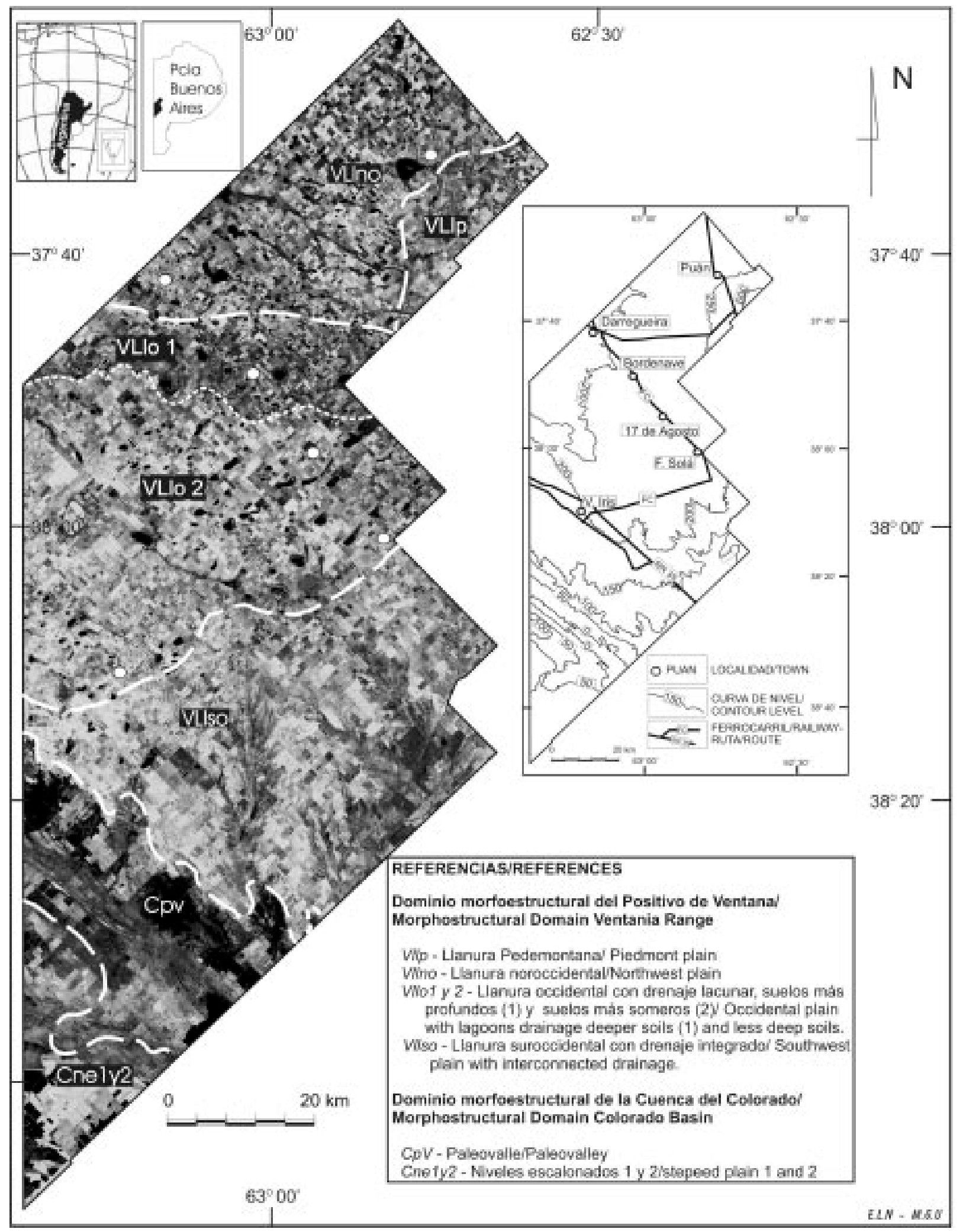

Figura 3: Unidades Geomórficas. Aplicación de CLUT, combinación de las bandas 2, 3 y 4 con realce a través de la ecualización del histograma. Ubicación de las principales localidades. Geomorphic Units. Using of CLUT. Combination of Bands 2, 3 and 4 with contrast enhacement in image data by using histogram equalization. Location of the main towns. 
Para el reconocimiento de condiciones diferenciales dentro de las unidades geomórficas, imposibles de discenir en las bandas en forma independiente y procurando una mayor definición, se procedió a la composición de las mismas. De las pruebas realizadas, resultó la mejor combinación la de las bandas 2, 3 y 4 (figura 3).

En esta se puede observar el resultado de la imagen TM transformada, traducida a gama de gris, que resultó de aplicar la CLUT en la que se asigna color azul a la banda 2 (verde espectral), color rojo a banda 3 (rojo espectral) y color verde a banda 4 (infrarrojo espectral), en la que se aplicó, como técnica de realce, la ecualización del histograma.

De esta operación surgió para el total de la superficie del partido, la posibilidad de introducir subdivisiones en las unidades geomórficas, en particular para las unidades VLlo y VLIso. En el primer caso se

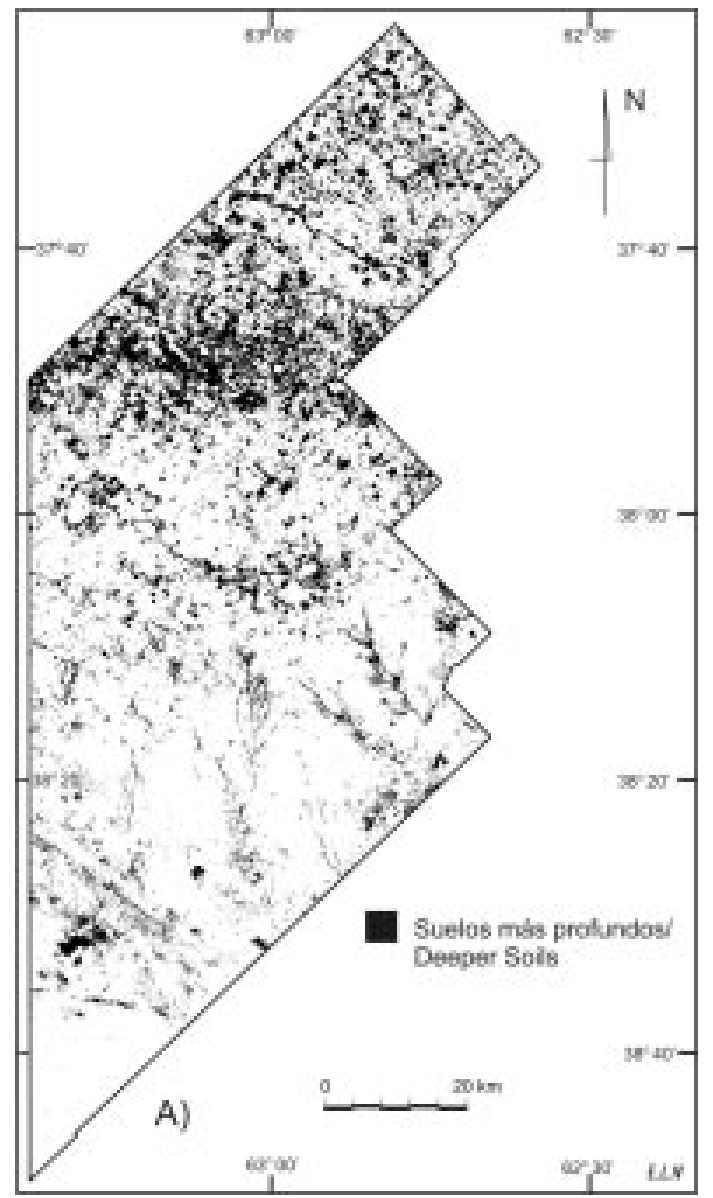

Figura 4: A) Imagen booleana donde se destaca la población de niveles visuales (ND) asociados a suelos más profundos [combinación banda 2, verde espectral (filtro azul) y banda 4, infrarrojo espectral (filtro verde)]. Boolen Image showing population of visual levels in relation with deeper soils [combination band 2, spectral green (blue filter) and band 4, near red (green filter)]. pudo diferenciar, dentro del plano de la llanura, entre mayor profundidad de suelos al norte y más someros al sur (figura 3). En el segundo se confirmó bien el límite entre lo que es planicie con suelos característicamente someros y las áreas en pendientes, generalmente cubiertas por monte o por depósitos de tipo coluvial, siempre más espesos que la cobertura de la planicie. Fue posible estblecer a partir de esta imagen, una asociación de niveles visuales de colores en relación a la diferente profundidad de los suelos. De esta forma, se obtuvo una imagen booleana en la que los tonos verdes azulados [combinación banda 2, verde espectral (filtro azul) y banda 4, infrarrojo espectral (filtro verde)], estaban asociados a suelos más profundos. Por otra parte, y a partir de tonalidades rojizas dadas fundamentalmente por la banda 3, rojo espectral (filtro rojo), se pudo obtener una imagen booleana en la que se destacan los suelos más someros (figura 4A y 4B).

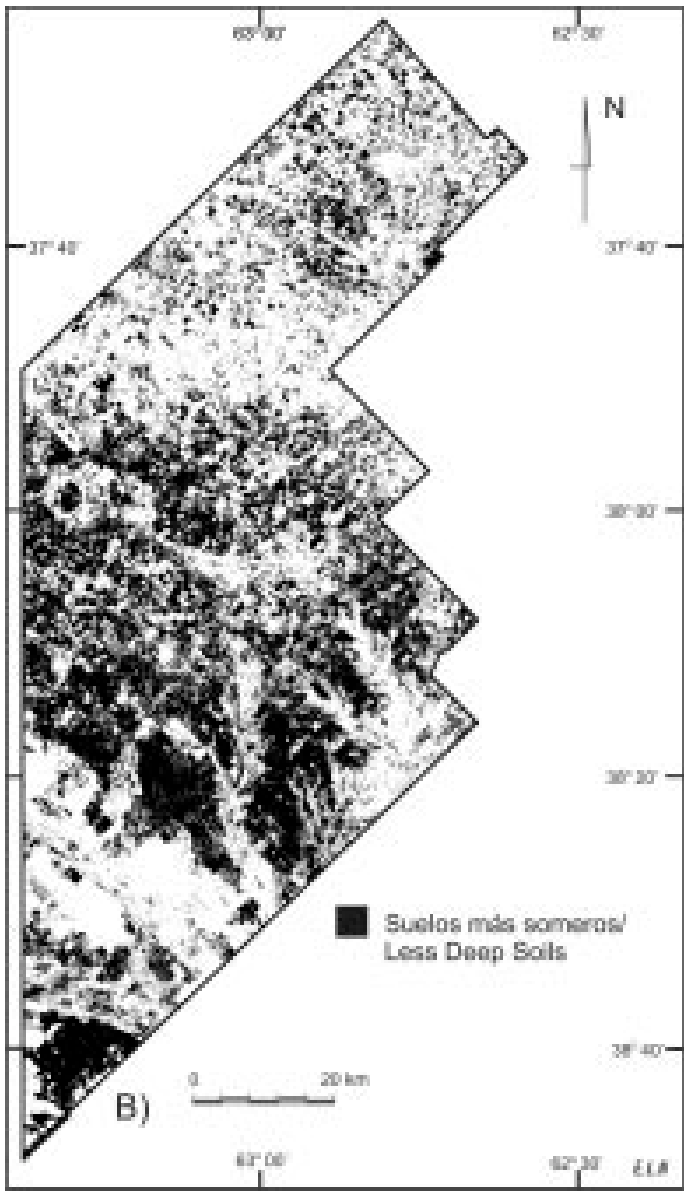

Figura 4: B) Imagen booleana donde se destaca la población de niveles visuales asociados a suelos menos profundos [fundamentalmente banda 3 (filtro rojo)]. Boolen Image showing population of visual levels in relation with less deep soils [mainly band 3, spectral red (red filter)]. 
NAVARRO, E. et al. Caracterización de las condiciones del drenaje...

\section{ANÁLISIS DE COMPONENTES PRINCIPALES}

El tratamiento matemático multivariado de los datos permite analizar, describir e interpretar individuos definidos por más de una variable. Particularmente, el Análisis de Componentes Principales (ACP) consiste en reemplazar variables originales por otras que resultan ser combinación lineal de las mismas (Pla 1986). Se simplifica así la estructura original de los datos, permitiendo pasar de un hiperespacio a otro susceptible de ser representado gráficamente (Cuadras 1981).

El carácter multiespectral y multitemporal de las imágenes digitales satelitales permiten la realización de este tipo de transformación, de manera tal que se obtiene un nuevo set de imágenes, en las que cada pixel nuevo se vincula a la reflectancia del pixel original, a través de una transformación lineal. De esta forma, la información esencial de las bandas originales puede ser preservada en un número reducido de dimensiones transformadas (Richards 1995).

La aplicación de este procedimiento matemático resultó de interés en la caracterización digital de unidades morfográficas, ya que permitió resaltar en forma clara, vías difusas de escurrimiento superficial y/o subsuperficial, y variaciones en cuerpos lacunares, posiblemente debidas a cambios en la profundidad $y / 0$ carga sedimentaria o salina en los mismos. Por tratarse de un análisis monotemporal, las zonas discriminadas corresponden a diferentes condiciones en terreno y no a variaciones secuenciales.

Aquí se trabajó con la matriz de Covarianza, teniendo presente que las variables empleadas en su desarrollo están expresadas en la misma unidad, ya que se trata de valores de reflectancia, y que además, era importante que cada una de las bandas mantuviera su valor relativo. Para el caso resultó de interés la imagen obtenida a partir del Tercer Componente Principal (3CP).

En la tabla 2 puede observarse los autovalores y porcentaje de correlación de cada una de las bandas con los CP. En particular el 3CP explica el $9.6 \%$ de la varianza total y contrasta fuertemente la banda del infrarrojo cercano (banda 4) con las del visible (banda 1, 2 y 3), infrarrojo medio (banda7) y termal (banda 6). Se puede también observar, en cuanto a la correlación de las variables con este componente, que la mayor correlación positiva está dada fundamentalmente por la banda 4 $(+0.75)$ y representa un $56 \%$, mientras que las correlaciones negativas están expresadas en esencia, por el conjunto del visible (banda 1: -0.20 , banda 2:0.11 y banda 3 : -0.16 ) totalizando un $8.1 \%$ y por las bandas $6(-0.26)$ y banda $7(-0.25)$ que representan respectivamente, el $6.9 \%$ y $6.4 \%$ de la correlación.

Tabla 2: Porcentaje de varianza asociado a cada componente principal (CP), autovalores y relación entre cada variable (banda) y los diferentes CP. Variance percentage associate with each principal component $(P C)$, eigenvalues and relation among variables (bands) and different $P C s$.

\begin{tabular}{||c||c|c|c|c|c|c|c||}
\hline COMPONENT & C 1 & C 2 & C 3 & C 4 & C 5 & C 6 & C 7 \\
\hline \% var. & 63.74 & 22.92 & $\mathbf{9 . 6 0}$ & 1.78 & 1.30 & 0.59 & 0.07 \\
\hline Eigenval. & 820.28 & 294.91 & $\mathbf{1 2 3 . 5 8}$ & 22.86 & 16.79 & 7.62 & 0.91 \\
\hline \hline LOADING & C 1 & C 2 & $\mathbf{C ~ 3}$ & C 4 & C 5 & C 6 & C 7 \\
\hline \hline PuanBnd1 & 0.6733 & -0.6975 & $\mathbf{- 0 . 2 0 1 4}$ & -0.0294 & 0.0197 & -0.1355 & -0.0191 \\
\hline PuanBnd2 & 0.7377 & -0.6564 & $-\mathbf{0 . 1 1 6 9}$ & -0.0234 & -0.0002 & 0.0126 & 0.1027 \\
\hline PuanBnd3 & 0.8224 & -0.5256 & $\mathbf{- 0 . 1 6 3 0}$ & -0.0342 & 0.0066 & 0.1502 & -0.0208 \\
\hline PuanBnd4 & 0.5606 & -0.3323 & $\mathbf{0 . 7 4 9 1}$ & 0.1182 & -0.0083 & -0.0034 & -0.0036 \\
\hline PuanBnd5 & 0.9010 & 0.4143 & $\mathbf{0 . 0 6 5 7}$ & -0.1040 & 0.0226 & -0.0114 & 0.0007 \\
\hline PuanBnd6 & 0.5109 & 0.3525 & $\mathbf{- 0 . 2 6 4 4}$ & 0.3829 & 0.6221 & 0.0095 & 0.0040 \\
\hline PuanBnd7 & 0.8612 & 0.3366 & $\mathbf{- 0 . 2 5 3 1}$ & 0.2410 & -0.1486 & -0.0090 & -0.0001 \\
\hline
\end{tabular}


Uno de los rasgos destacables en esta imagen, corresponde a la mejor visualización de las vías de escurrimiento, particularmente importante en la unidad VLIso según muestra un detalle de la misma en la figura 5. Fue posible además diferenciar otras particularidades del terreno, especialmente dentro de los cuerpos lacunares. En una ventana de la imagen de este $3 \mathrm{CP}$ (figura 6), donde se muestra un conjunto de cuerpos ácueos, el histograma de frecuencia permite separar tres subpoblaciones de pixeles, resultando de interés, las comprendidas a los intervalos de $-32 \mathrm{a}-21$ y $-21 \mathrm{a}-11$ por estar vinculados con dichas superficies de agua (figura 7).

Chuvieco (2000) establece que la variabilidad de las características del agua es más fácilmente detectable en el visible y se relaciona con profundidad, materiales en suspensión y rugosidad de la superficie. La absortividad será mayor cuanto más profundo es el cuerpo de agua, considerando este autor que la profundidad de agua que puede estimarse respectivamente con las bandas del azul, verde y rojo espectral alcanza los $6,4 \mathrm{~m}, 3 \mathrm{~m}$ y 2,1 $\mathrm{m}$.

En el presente trabajo, gran parte de la correlación negativa de este $3 \mathrm{CP}$ está asociada a las bandas del visible, en consecuencia toda la información brindada por cada una de ellas tiene un efecto sinérgico a través del resumen que expresa este componente. Se puede establecer entonces que dicha diferencia tonal estaría asociada, en los cuerpos lacunares, fundamentalmente a las diferentes profundidades de los mismos, teniendo presente que en la región esta profundidad no supera en general los $9 \mathrm{~m}$.

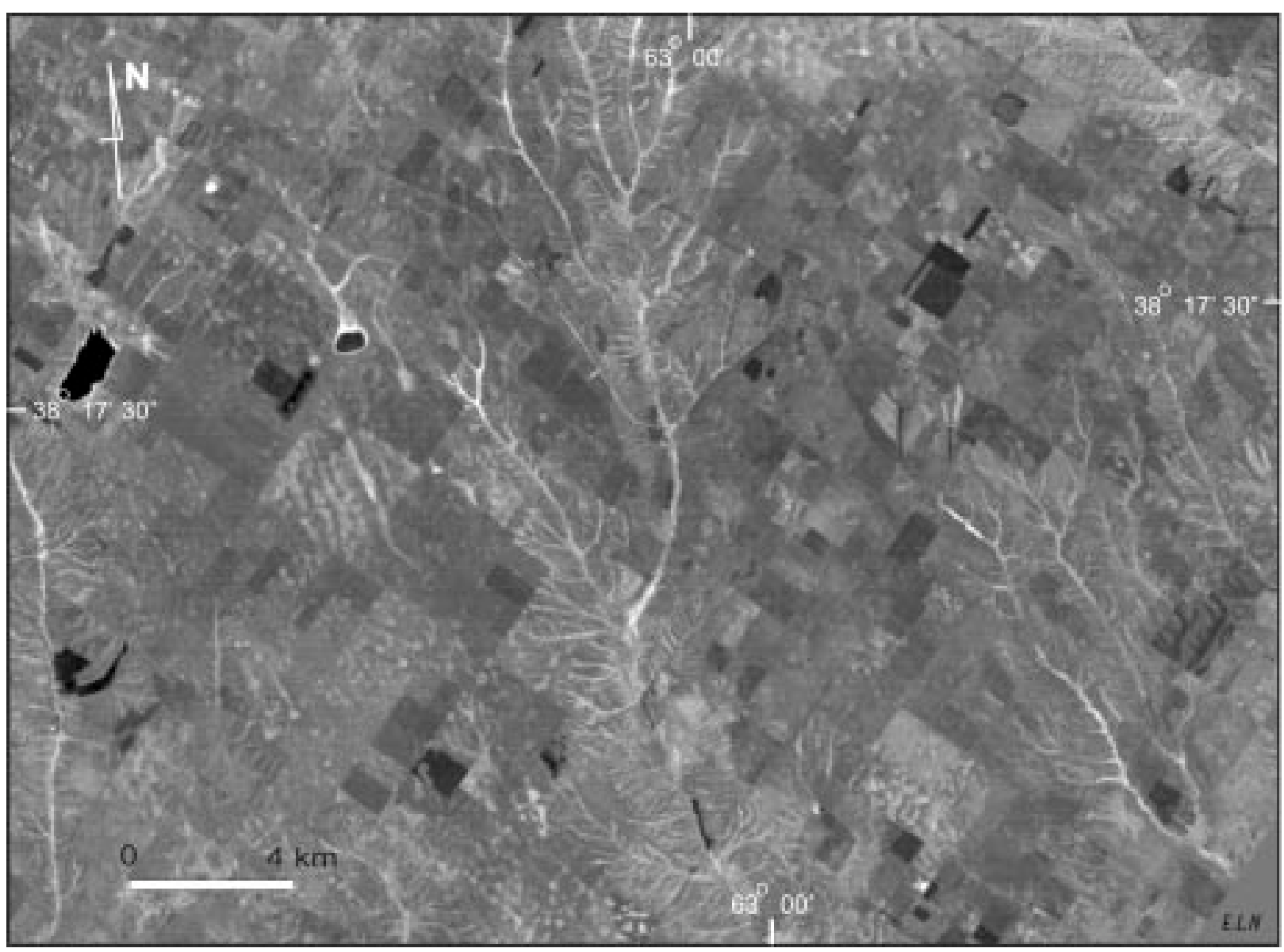

Figura 5: Ventana de la imagen del Tercer Componente Principal (3CP) en la que se destacan las vias de escurrimientos. Image window of the third principal component (3PC) where the runoff is emphasized 


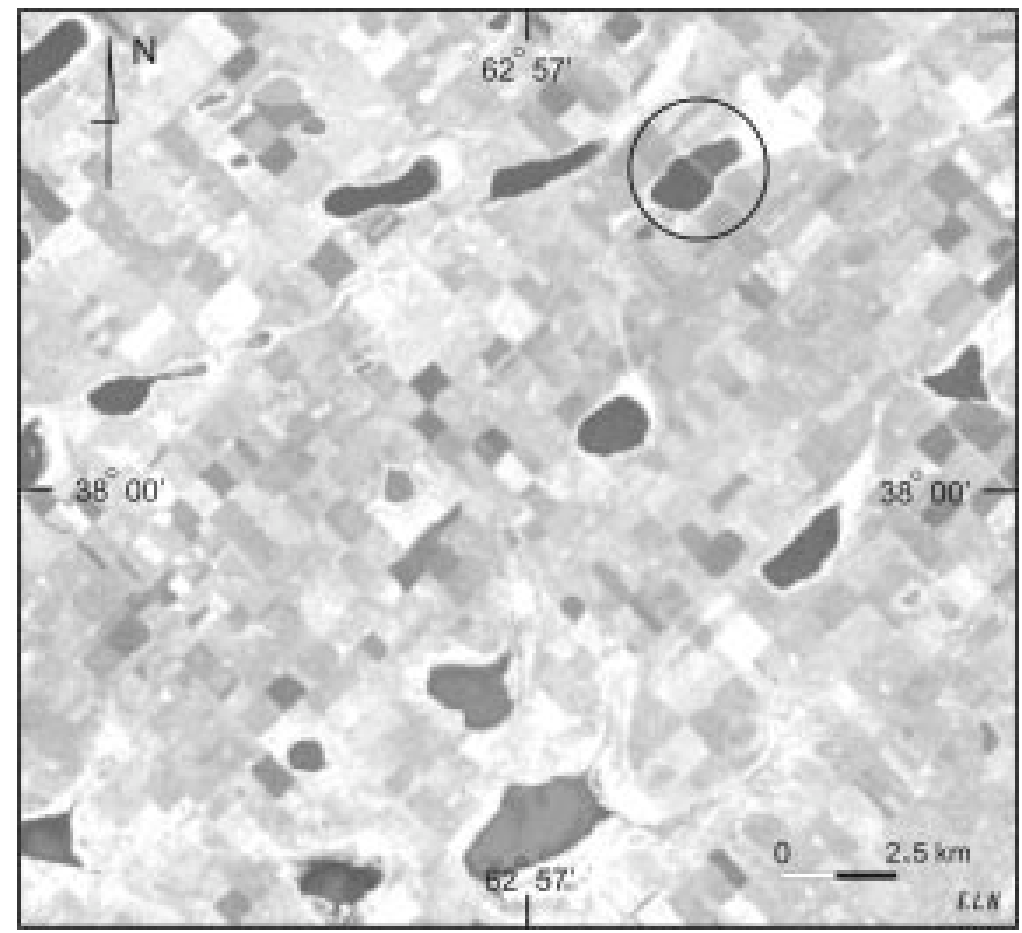

Figura 6: Ventana de la imagen del Tercer Componente Principal (3CP) en la que se destacan los cuerpos lacunares seleccionados. El círculo muestra el endicamiento producido por los alteos; los diferentes tonos a ambos lados del mismo indican profundidades diferenciales. Image window of the third principal component (3PC) showing the ponds selected. In the circle, the obstacle caused by the barricades is showed. The different tones at both sides of the barricades indicate differential dephts.

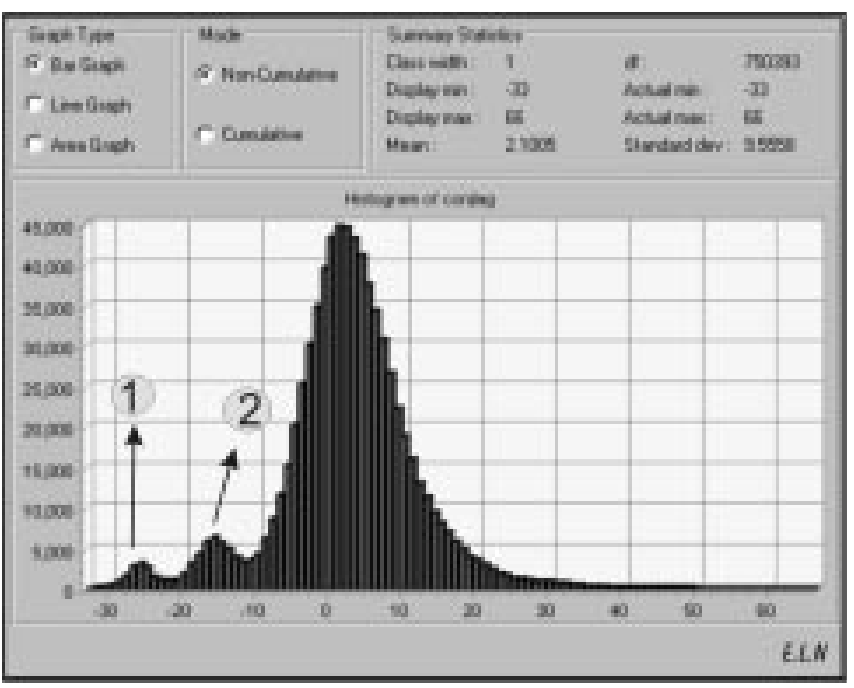

Figura 7: Histograma de frecuencia de la figura 6 en la que se destacan las tres poblaciones de pixeles. La población 1 corresponde a los cuerpos de agua y la población 2 a cuerpos de agua y parcelas. Image Histogram of figure 6 showing three pixels populations. Population 1 corresponds to water bodies and population 2 corresponds to water bodies and lands.

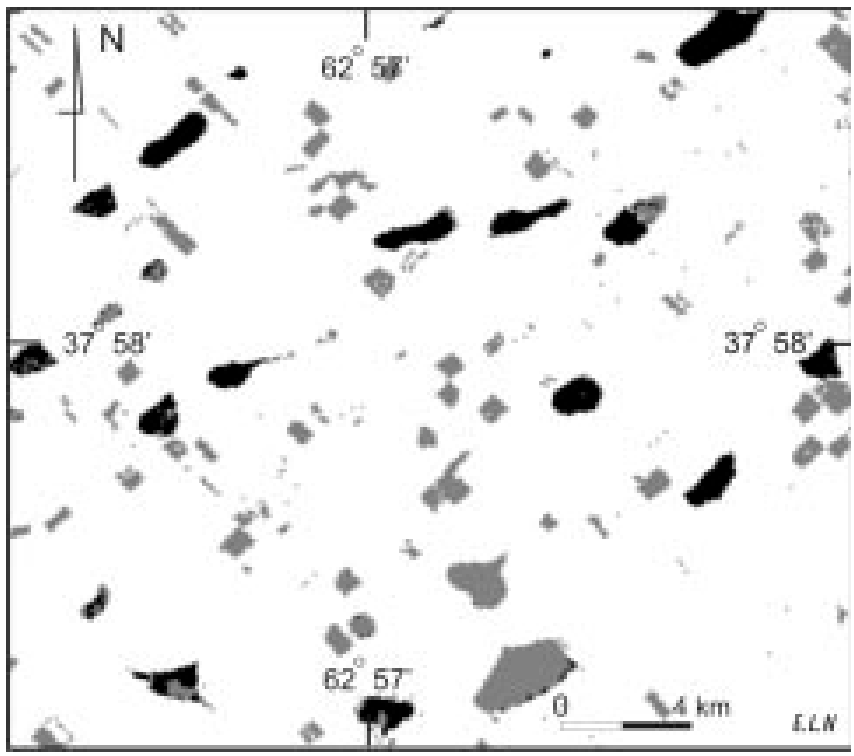

Figura 8: Clasificación a partir del histograma de la imagen de la figura 6. El tono oscuro corresponde a cuerpos de agua más profundos y el tono gris, a cuerpos más someros y parcelas sin vegetación o con vegetación con baja actividad fotosintética. Classification starting from the image's histogram of figure 6 . The dark tone indicates deeper water bodies and the grey tone shallower water bodies and lands without vegetation or with low photosinthetic activity. 
La figura 6 de esta ventana del 3CP muestra tal relación. Los tonos más oscuros y más claros de los cuerpos individualizados están caracterizados respectivamente por los identificadores negativos más altos (subpoblación 1) y más bajos (subpoblación 2). A partir de esta imagen, se realizó una reclasificación (figura 8), teniendo presente los intervalos -32 a -21 y -21 a -11 , donde quedan definidos dos grupos tonales, los más oscuros, correlacionados con los valores más negativos, asociados a cuerpos lacunares más profundos, y los más claros, con los valores más positivos, asociados a cuerpos acueos someros y parcelas sin vegetación o con vegetación con baja actividad fotosintética.

A modo de comprobación para la correlación de tonos y profundidades, en la figura 6 , se observa un cuerpo ácueo atravesado por un camino con terraplén, que actúa como elemento de endicamiento durante los períodos húmedos. Esto genera dos sectores de drenaje diferencial, uno con mayor profundidad de agua visualizado con tono oscuro y otro, aguas abajo del mismo, de tono más claro. El hecho que marca esta diferencia a ambos lados del terraplén, se debe a que por su interferencia se acumula un cuerpo de agua equivalente a la altitud del mismo, trasvasándose sólo el agua que puede superar dicho nivel y que en caso de hacerlo genera aguas abajo un cuerpo de agua siempre más somero.

\section{CONCLUSIONES}

De lo expresado en la discusión y resultados en cuanto a los geaoambientes presentes y al tratamiento digital de imágenes, se arriba a las siguientes conclusiones

1- El análisis geomorfológico y tratamiento digital de imágenes ofrecen datos que se complementan, resultando por igual necesarias ambas fuentes de información.

2- Las unidades geomorfológicas, predeterminadas en un trabajo anterior por condiciones de relieve, drenaje y formaciones superficiales, se confirman y subdividen a través del análisis de imágenes satelitales. Se corroboran así los seis grandes geoambientes: Llanura Pedemontana (VLIpd), Llanura Noroccidental (VIIno), Llanura Occidental (VIlo), Llanura Suroccidental (Vllso), Paleovalle Complejo ( $\mathrm{CpV}$ ) y Niveles escalonados 1 y 2 (CNe1y2).

3- El tratamiento digital de imágenes, a través de la interpretación directa del IRC (Infrarrojo espectral cercano) (figura 2) hizo posible seleccionar todos los sectores cubiertos por agua y su cuantificación areal.

4- El empleo de CLUT (Color Look Up Table) permitió: a) introducir una subdivisión en la unidad VLIso por profundidad de suelo (figura 3); b) reconocer en el Partido, las áreas con suelos someros y profundos (figura $4 \mathrm{~A}$ y B) y; c) definir límites no delineados por razones de escala para la unidad VLIso, en la transición entre planicie y areas en pendientes, o su contacto con la unidad CpV (figura 5).

5- La aplicación de Análisis de Componentes Principales (ACP), en particular el Tercer Componente Principal (3CP), permitió reconocer mucho más claramente vias de drenaje, funcionales o no, dentro de la unidad VLIso, como así también poder discriminar aumentando el detalle, diferentes profundidades de los cuerpos lacunares que fueron agrupados en dos categorías (figura 8).

\section{AGRADECIMIENTOS}

Se agradece la posibilidad de haber realizado el presente trabajo, a la Comisión Nacional de Actividades Espaciales (CONAE) que brindó las imágenes multiespectrales, a la Secretaria de Ciencia y Tecnología de la Universidad Nacional del Sur por el financiamiento del proyecto, a la Comisión Investigaciones Científica por el aporte a través de un cargo para investigación y desarrollo, como así también, a los correctores del presente manuscrito por las valiosas sugerencias y críticas realizadas.

\section{REFERENCIAS}

Cabrera, A.L. 1976. Regiones fitogeográficas argentinas. Buenos Aires, Enc. Arg. Agr. y Jard. TII. Fasc. 2, Acmé, 57 p.

Clark Labs. 1999. Idrisi 32 for Windows. Clark University. Conjunto de programas $1 \mathrm{CD}-\mathrm{ROM}$.

Cuadras, C.M. 1981. Métodos de análisis multivariante. 2 ed. Barcelona, Bunibar, 642 p.
Chuvieco, E. 2000. Fundamentos de teledetección espacial. $3^{\text {nra }}$ ed. revisada, Madrid, Rialp, 568 p.

Eros Data Center. 1999. Imagen landsat tematic mapper. USA.

Forte Lay J., Quintela R., Scarpatti O. 1989. Evolución de las características hidrometeorológicas de la Llanura 
Pampeana Argentina. In: COLOQUIO INTERNACIONALE DE HIDROLOGÍA DE GRANDES LLANURAS, 1989, Buenos Aires. Actas... Buenos Aires, 2: 141- 149.

González Uriarte M. 1984. Características geomorfológicas de la porción continental que rodea la bahía Blanca. Provincia de Buenos Aires. In: CONG. GEOL. ARG., 9, 1984, Bariloche. Actas... Bariloche, 556-576.

González Uriarte M., Paoloni J.D., Navarro E.L., Fiorentino H., Sequeira M. 2000. Relaciones entre paisaje, escurrimiento superficial y calidad del agua freática en el Partido de Puán (Buenos Aires. Argentina). In: INTERNATIONAL SOIL CONSERVATION ORGANIZATION CONFERENCE, 11, 2000, Buenos Aires. Resumen... Buenos Aires, p 101. v.1

Instituto Geografico Militar. 1957-1972 (Buenos Aires). Cartas topográficas de la República Argentina. Escalas 1:500000, 1:100000 y 1:50000. Hojas: Santa Rosa (3763) y Bahía Blanca (3963).

Instituto Geográfico Militar. 1999 (Buenos Aires). Cartas Satelital de la República Argentina. Escalas 1:250000 y 1:100000. Hojas: Santa Rosa (3763-III y IV) y Bahía Blanca (3963 I y II).
Instituto Nacional de Estadísticas y Censo (Indec). 1991. Censo Nacional 1991. Biblioteca Nacional. Buenos Aires, República Argentina.

Instituto Nacional de Tecnología Agropecuaria (Buenos Aires). 1989. Mapa de Suelos de la Provincia de Buenos Aires. Escala 1:500000.

Pla L. E. 1986. Análisis multivariado: método de componentes principales. Washington D. C., Secr. OEA. 89 p. (Monog. 27).

Richards J.A., 1995. Remote sensing digital image analysis. An Introduction. 2 ed. Berlin, Springer-Verlag, 333 p.

Strahler A. 1989. Clasificación de los climas. In: Strahler A. Geografía Física. Barcelona, Omega, p. 240-252.

Soil Survey Staff. 1999. Keys to Soil Taxonomy. United States Department of Agriculture. 6. ed. Washington.

Van Wanbecke A. C., Scoppa C. 1980. Las taxas climáticas de los suelos argentinos. Castelar, INTA, Centro Invest. de Recursos Naturales, 65 p. (publicación n. 168).

Recebido em 23 dez. 2001 Aceito em 14 mar. 2002 